\title{
The Design and Construction of the MICE Spectrometer Solenoids
}

\author{
Bert Wang Member IEEE, Bob Wahrer, Clyde Taylor, L. Xu, J.Y. Chen, M. Wang, Tiki Juang, \\ Michael S. Zisman, Steve P. Virostek, and Michael A. Green Member IEEE
}

\begin{abstract}
The purpose of the MICE spectrometer solenoid is to provide a uniform field for a scintillating fiber tracker. The uniform field is produced by a long center coil and two short end coils. Together, they produce 4T field with a uniformity of better than $1 \%$ over a detector region of $1000 \mathrm{~mm}$ long and $300 \mathrm{~mm}$ in diameter. Throughout most of the detector region, the field uniformity is better than $0.3 \%$. In addition to the uniform field coils, we have two match coils. These two coils can be independently adjusted to match uniform field region to the focusing coil field. The coil package length is $2544 \mathrm{~mm}$. We present the spectrometer solenoid cold mass design, the powering and quench protection circuits, and the cryogenic cooling system based on using three cryocoolers with re-condensers.
\end{abstract}

Index Terms - Magnet Design, Magnet Fabrication, and Magnet Cooling

\section{INTRODUCTION}

$\mathrm{T}$ HE key accelerating and storing muon beams is muon beam cooling [1]. Muon beam cooling will be demonstrated by the Muon Ionization Cooling Experiment (MICE) at the Rutherford Appleton Laboratory in the UK [2].

The cooling channel for MICE consists of three types of solenoid magnets; 1) the three focusing magnets that are around the liquid hydrogen absorbers [3], 2) the two coupling magnets that surround the RF cavities that re-accelerate the muons to restore their longitudinal momentum [4], and 3) the two spectrometer magnets that are used to analyze the muon beams entering and leaving the cooling channel [5].

Each spectrometer magnet consists of two match coils M1 and M2 and three-coil spectrometer section (E1, C and E2). M1 and M2 are used to match the spectrometer section with the MICE channel. The three-coil section produces a uniform magnetic field ( \pm 0.3 percent) within a region that is $1.0-\mathrm{m}$ long and $0.3-\mathrm{m}$ in diameter. The uniform field section contains a five-plane scintillating fiber detector for muon beam emittance analysis.

The spectrometer solenoid design is based on a design made by INFN Genoa [6]. When INFN Genoa dropped out of the

Manuscript received 26 August 2008. This work was supported by the Office of Science US Department of Energy under DOE contract DE-AC0205CH11231. DOE funding for the US Neutrino Factory Muon Collider Collaboration is greatly appreciated.

S. T. Wang, C. Taylor, X. Lu, J, Y. Chen, M. Wang, and T. Juang are with Wang NMR, Livermore CA, USA 94550. E-mail bert@wangnmr.com. M. S. Zisman, S. P. Virostek and M. A. Green, are with the Lawrence Berkeley National Laboratory, Berkeley, CA 94720, USA. The corresponding author is M. A. Green with LBNL. Phone +1-510-486-5598, Fax +1-510-486-6668, and e-mail: magreen@lbl.gov.gov).
MICE collaboration, the task of fabricating of the spectrometer magnets fell to the Lawrence Berkeley National Laboratory (LBNL). The LBNL design is based on the use of a $\mathrm{Nb}$-Ti superconductor with a copper to superconductor ratio of four [5]. The LBNL magnet is designed to be cooled using three $1.5 \mathrm{~W}$ pulse tube coolers.

\section{Magnet Design}

The magnet design parameters are shown in Table I. In Table I, Z1 and Z2 are the axial distances from the match coil end of the cold mass to the two ends of the coil. The coil length is $\mathrm{Z} 2-\mathrm{Z} 1$. $\mathrm{R} 1$ is the coil inner radius; $\mathrm{R} 2$ is the coil outer radius. The coil thickness is R2 - R1.

TABle I. The Spectrometer Magnet CoIl Parameters

\begin{tabular}{lccccc}
\hline \hline \multicolumn{1}{c}{ Parameter } & M1 & M2 & E1 & C & E2 \\
\hline No. Turns/Layer & 115 & 114 & 64 & 768 & 64 \\
No. of Layers & 42 & 28 & 56 & 20 & 62 \\
Total Turns & 4830 & 3192 & 3584 & 15360 & 3068 \\
Z1 (mm) & 23.4 & 464.3 & 908.7 & 1056.9 & 2408.7 \\
Z2 (mm) & 224.6 & 663.8 & 1019.3 & 2371.2 & 2519.3 \\
R1 (mm) & 258.0 & 258.0 & 258.0 & 258.0 & 258.0 \\
R2 (mm) & 304.5 & 288.0 & 319.7 & 280.4 & 326.3 \\
Delta Z (mm) & 201.2 & 199.5 & 110.6 & 1314.3 & 110.6 \\
Delta R (mm) & 46.5 & 30.6 & 61.7 & 22.4 & 68.3 \\
\hline \hline
\end{tabular}

The bobbin for the five coils is machined from a single forged 6061-T6-aluminum cylinder (see Fig. 1) to contain the magnet axial load. The magnet radial load is supported by the conductor in the coil and aluminum band of 6 to $10 \mathrm{~mm}$ in thickness. Coil winding is shown in Fig 2. The magnet after winding and banding is shown in Fig. 3.

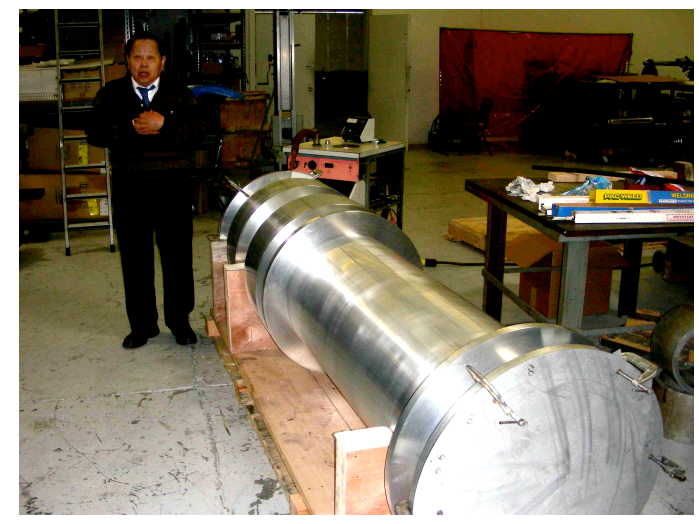

Fig. 1. The Magnet Forged 6061-T6 Mandrel during Machining. 


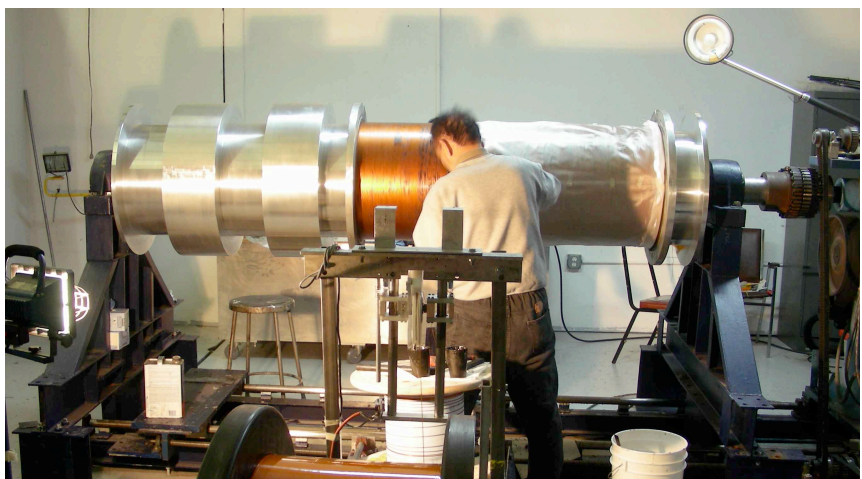

Fig. 2. Winding the spectrometer Solenoid Center Coil at Wang NMR.

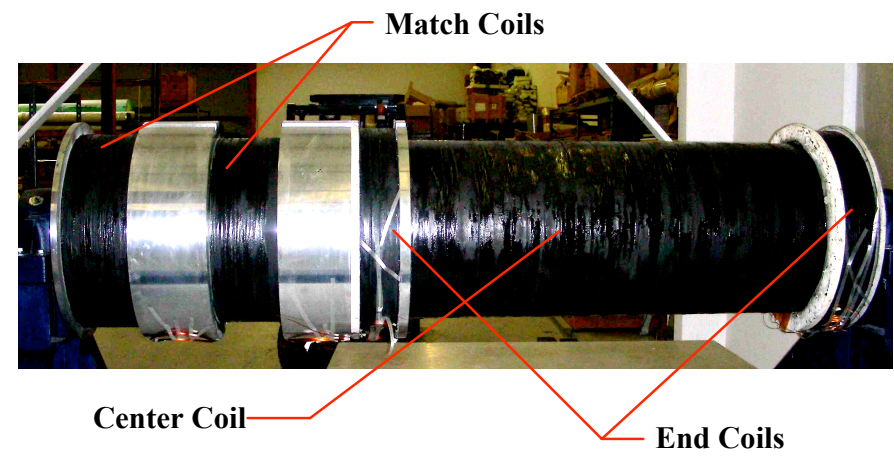

Fig. 3. A Wound and Banded Spectrometer Solenoid at Wang NMR.

The space outside of the magnet coils shown in Fig 3 and the cold mass helium vessel shell contains liquid helium when the magnet is in operation. The net volume of the helium vessel is about 180 liters. The helium vessel shell is made of $12.7 \mathrm{~mm}$ 6061-T6 aluminum. The finished cold mass helium vessel for the first magnet is shown in Fig. 4.

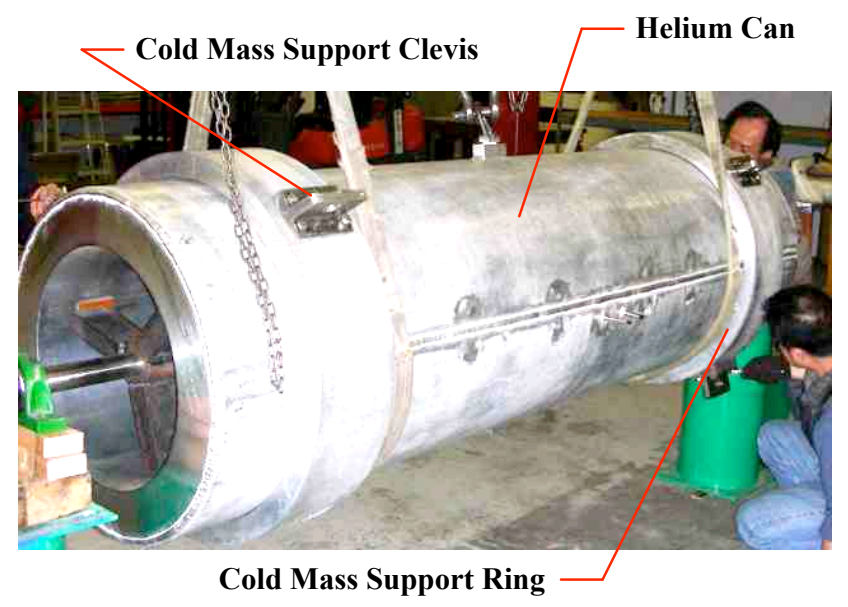

Fig. 4. The Finished Cold Mass Helium Vessel for the Spectrometer solenoid.

Table II summarizes the net magnetic axial coil forces, the magnetic hoop stress in the coil, and the magnetic axial coil stress against the mandrel when the magnet is operated at its worst-case excitation. A positive sign for the axial force indicates that the force is in a direction toward the spectrometer end of the magnet (the end farthest from the center of the MICE channel). It is clear that the worst-case magnetic stresses in the spectrometer magnet coils are modest.
Table II. Net Coil Axial Force, Hoop Stress And Axial PRESSURE UNDER THE WORST-CASE EXCITATION*

\begin{tabular}{cccc}
\hline \hline Coil & $\begin{array}{c}\text { Net Force } \\
\text { (tons) }\end{array}$ & $\begin{array}{c}\text { Hoop Stress } \\
\text { (MPa) }\end{array}$ & $\begin{array}{c}\text { Axial Stress } \\
\text { (MPa) }\end{array}$ \\
\hline M1 & +41 & 52.8 & -17.9 \\
M2 & +16 & 63.0 & -12.2 \\
E1 & +105 & 81.8 & -29.2 \\
Center & +7 & 80.2 & -3.88 \\
E2 & -169 & 86.5 & 20.5 \\
\hline \hline
\end{tabular}

* The worst-case forces occur at a muon momentum of $240 \mathrm{MeV/c}$.

The magnet has a copper matrix conductor wound on an aluminum mandrel. When the magnet is cooled down to $4 \mathrm{~K}$, the coils are put in axial compression. The axial compression stresses are larger than the axial magnetic stresses. The magnet coil was wound under tension and banded with aluminum. The magnet was designed so that the coil doesn't lift from the mandrel during charging. The tensile stresses in the coil and mandrel change during the cool down. These changes can be as large as the tensile stress in the coil due to excitation. In all cases, the overall stress level is acceptable.

Table III summarizes the magnet coil self-inductance, the coil design current for high momentum muons $(240 \mathrm{MeV} / \mathrm{c}$ ), the stored energy of the magnet at design current, and the peak magnetic field for the five solenoid coils operating at their design current. Table III also shows the self-inductance for the three coil set that makes up the spectrometer section and the self-inductance for all five coils connected in series.

TABle III. InduCtAnCE, STOREd ENERGY AND PEAK FIELD

\begin{tabular}{lccccc}
\hline \hline \multicolumn{1}{c}{ Parameter } & M1 & M2 & E1 & C & E2 \\
\hline Coil Inductance (H) & 17.47 & 9.59 & 15.39 & 51.58 & 15.91 \\
Coil Design Current (A) & 253.8 & 263.6 & 226.6 & 269.9 & 240.7 \\
Coil Energy (MJ)* & 0.56 & 0.33 & 0.40 & 1.88 & 0.46 \\
Coil Peak Field (T)* $^{*}$ & 4.43 & 4.01 & 5.90 & 4.19 & 6.37 \\
\hline \hline
\end{tabular}

The self inductance of E1 + C + E2 $=80.67 \mathrm{H}$

The self inductance of all five coils in series $=109.94 \mathrm{H}$

The stored energy of all five coils in series at $275 \mathrm{~A}=4.16 \mathrm{MJ}$

Table IV summarizes the results of the 3D quench analyses on the spectrometer magnet. The quench protection for the magnet is passive. The two match coils each have back-toback diodes and a resistor across them. This reduces the hotspot temperature in coils M1 and M2. The end coils E1 and E2 of the three-spectrometer coil set also have back-to-back diodes and a resistor across them. The center (C) coil of the spectrometer solenoid set is sub-divided in two parts (layer 1 to layer 10 and from layer 11 to layer 20). Thus the three-coil set has a total of four sub-divisions (see Fig. 5).

TABLE IV. 3D MAGNET QUENCH ANALYSES

\begin{tabular}{|c|c|c|c|c|c|}
\hline Parameter & M1 & M2 & E1 & $\mathbf{C}$ & E2 \\
\hline Quench Time (s) & 2.4 & 3.6 & 4.4 & 3.0 & 4.2 \\
\hline Number of Divisions & 1 & 1 & 1 & 2 & 1 \\
\hline Max. Coil R $(\Omega)$ & 9.6 & 6.0 & 7.1 & 12.0 & 8.9 \\
\hline Max. Internal V (kV) & 1143 & 454 & 857 & 1637 & 1094 \\
\hline Max. Hot Spot T (K) & 135 & 83 & 131 & 86 & 155 \\
\hline
\end{tabular}




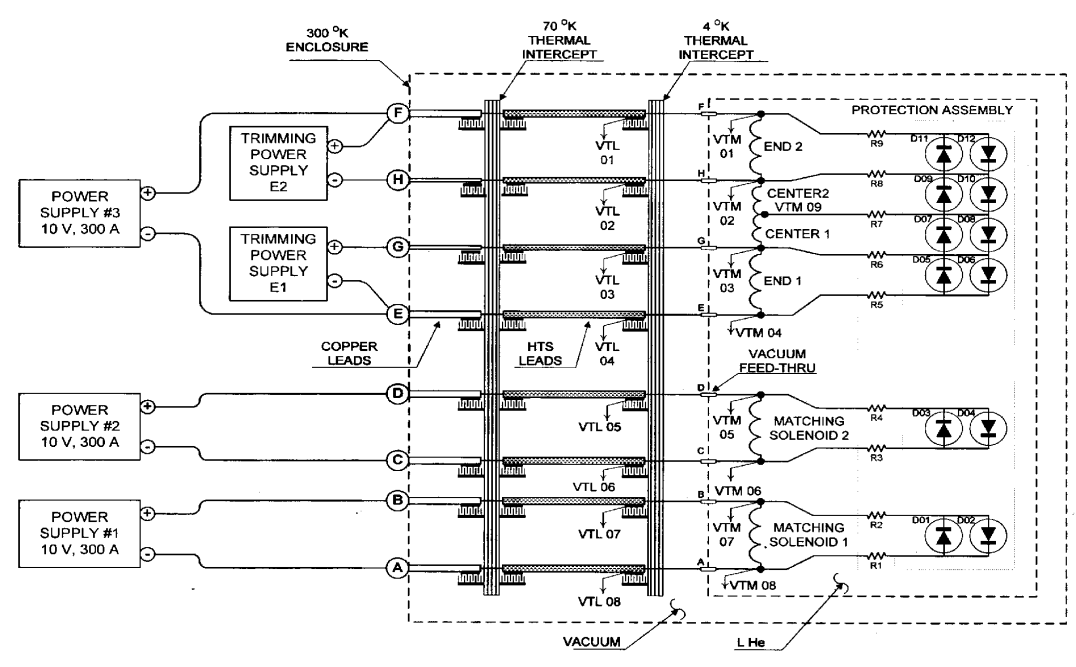

Fig. 5. The Quench Protection Circuits and Coil Excitation Circuits for a Spectrometer Magnet using Three 300-A and Two 60-A Power Supplies.

The role of the coil sub-division is to reduce the peak voltage and the peak hot-spot temperature [7]. The quench protection diodes are located within the liquid helium volume of the magnet. At $5 \mathrm{~K}$, the diode forward voltage is greater than 6 volts. The design of the quench protection system and rapid discharge system is based on a quench protection diode forward voltage of 4 volts [8]. The resistance in series with the cold diodes is small. As a result, very little of the magnet stored energy ends up in the diodes and the maximum internal voltage is inversely proportional to the number of magnet circuit sub-divisions [9].

Fig. 5 shows the quench protection system and powering circuit for a single spectrometer magnet. Each match coil will be powered by a power supply that delivers $300 \mathrm{~A}$ at $10 \mathrm{~V}$. The magnet discharge will be through a diode pack [8]. The three-coil spectrometer solenoid is connected in series using a single 300 A power supply that delivers a voltage up to $10 \mathrm{~V}$. The current end coils E1 and E2 will be adjusted using a pair of power supplies that will deliver $\pm 60 \mathrm{~A}$ at $\pm 5 \mathrm{~V}$.

\section{CRYOSTAT DESIGN}

The cryostat consists of $4.2 \mathrm{~K}$ helium vessel, a 60 to $80 \mathrm{~K}$ thermal shield, and a $300 \mathrm{~K}$ vacuum vessel. There is a service tower on the top of the magnet that contains three PT415 pulse tube coolers that generate $1.5 \mathrm{~W}$ at $4.2 \mathrm{~K}$ while generating about $55 \mathrm{~W}$ at about $55 \mathrm{~K}$. The coolers are mounted within the service tower in the drop-in mode, so they can be shipped separately from the magnet. Operating the coolers in the dropin mode adds about $0.25 \mathrm{~W}$ per cooler to the $4.2 \mathrm{~K}$ stage heat load and $\sim 2.5 \mathrm{~W}$ per cooler to the $55 \mathrm{~K}$ stage [10].

The service tower is designed with three vacuum insulated sleeves to allow removal of the coolers. The service tower also contains six 500-A HTS leads and two 100-A HTS leads that are thermally connected to the cooler first stages at the top (see Fig 6). The system is designed so the top ends of the HTS leads are at $60 \mathrm{~K}$. The lower ends of all eight HTS leads are connected to the $4 \mathrm{~K}$ magnet cold mass.

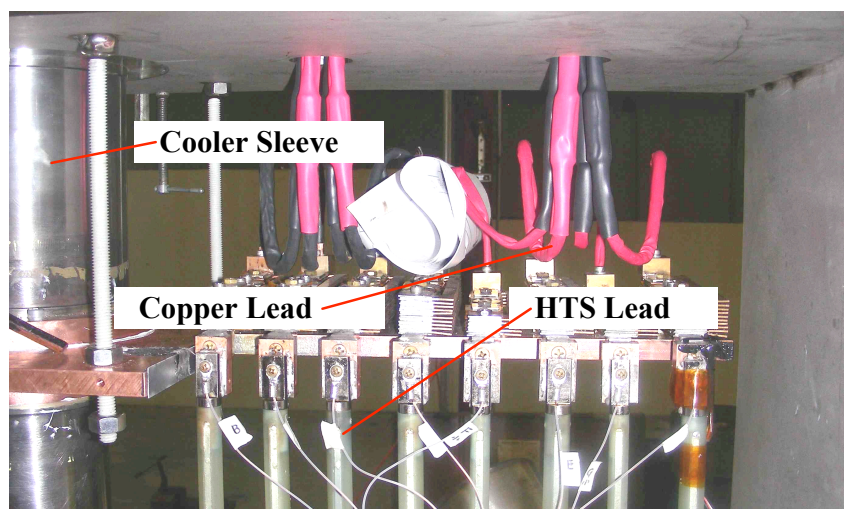

Fig. 6. The Upper End of the HTS Leads and The Copper Leads from $300 \mathrm{~K}$.

The helium vessel is designed to satisfy ASME pressure vessel code. The total liquid helium volume is $\sim 180$ liters. The helium vessel pressure rating is $0.41 \mathrm{MPa}(45 \mathrm{psig})$. The rupture disc pressure is set at $0.31 \mathrm{MPa}(30 \mathrm{psig})$. The relief valve pressure will be set at $0.17 \mathrm{MPa}(10 \mathrm{psig})$. The helium vessel contains one pre-cool tube (25-mm ID) and two vent tubes of $38-\mathrm{mm}$ diameter each. In addition, it has a $12-\mathrm{mm}$ diameter gas recovery tube and one 6-mm diameter liquid refill tube for three helium re-condensers. The cold mass is connected to the second stage through re-condensation loops. The design heat loads to both stages of the coolers is summarized in Table V.

The outer-cylindrical portion of the $80 \mathrm{~K}$ shield is made of $6.35-\mathrm{mm}$ thick 6061-T6-aluminum. The shield end plate and the bore cylindrical-shield are made of 4.8-mm thick 6061-T6 aluminum plates. The magnet $80 \mathrm{~K}$ shield and the HTS leads are conduction cooled to the cooler first stages.

The cryostat vacuum vessel is made of $20-\mathrm{mm}$ thick 304 stainless steel sheets. It is made to satisfy the ASME pressure vessel code to sustain with pressure rating of $0.1013 \mathrm{MPa}(\sim 1$ atm) in either direction. The vacuum vessel is protected from internal pressurization by a $25-\mathrm{mm}$ diameter relief valve that is part of the pumping system. 
Table V. The Design Spectrometer Magnet Heat Loads

\begin{tabular}{lcc}
\hline \hline \multicolumn{1}{c}{ Heat Load Source } & $\begin{array}{c}\text { 60 K heat } \\
\text { Load }(\mathbf{W})\end{array}$ & $\begin{array}{c}\text { 4 K Heat } \\
\text { Load (mW) }\end{array}$ \\
\hline Radiation to 80 K Shield & 10.8 & ---- \\
Radiation to 4 K cold Mass & ---- & $\sim 50$ \\
Cold Mass Support & 6.4 & $\sim 310$ \\
Shield Cold Mass Support & $\sim 1.2$ & --- \\
Neck Tubes & $\sim 1.9$ & $\sim 60$ \\
Cooler Sleeve Tubes & $\sim 7.5$ & $\sim 750$ \\
Instrument Wires & $\sim 1.0$ & $\sim 50$ \\
Magnet Leads & 91.4 & 870 \\
Joule heating in Joints at 4 K & ---- & $\sim 400$ \\
$\quad$ Total Heat Load (W) & $\mathbf{1 2 0 . 2}$ & $\mathbf{2 . 4 9}$ \\
\hline \hline
\end{tabular}

The design heat loads shown in Table V suggest that the magnet can be run on two coolers. This is unlikely. The first stage temperature given in Table $\mathrm{V}$ is based on using three coolers. In order to achieve a first stage temperature of $60 \mathrm{~K}$ or below, one must reduce the heat load into the $1^{\text {st }}$ stage, and one must have a perfect thermal connection between the shield and the cooler $1^{\text {st }}$ stage. The $1^{\text {st }}$ stage heat load is dominated by the eight copper-leads from $300 \mathrm{~K}$. Using drop-in coolers means that there will be a $\Delta \mathrm{T}$ from the sleeve to the cooler first stage in addition to the $\Delta \mathrm{T}$ within the shield and lead assembly. If one reduces the number of coolers from three to two, the temperature of the shield, the HTS leads, and cooler $1^{\text {st }}$ stage will go up, which increases the $2^{\text {nd }}$ stage heat load.

\section{Assembly of the First SpeCtrometer Magnet}

The Magnet 1 was assembled in the spring of 2008. Magnet 2 will be finished in early 2009. The cold mass was insulated with 6 layers of multi-layer insulation (MLI). The cold mass was assembled with the MLI insulated outer shield (30 layers of MLI outside the shield) into the vacuum vessel. The cold mass supports were adjusted to provide the required pre-stress in the support bands and to center the cold mass with the center of an external flange on the vacuum vessel. The cold mass and shield assembly in the vacuum vessel is shown in Fig. 7. The finished magnet is shown in Fig. 8.

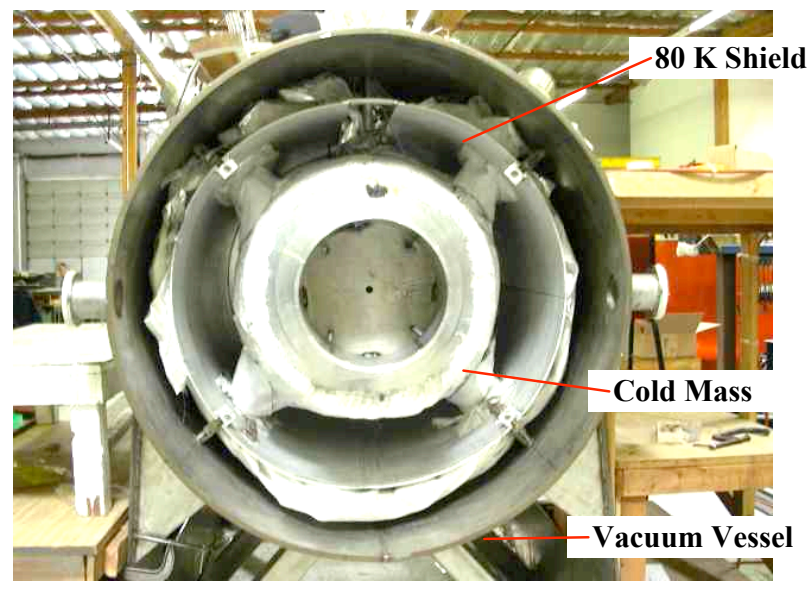

Fig. 7. The Assembly of the Cold Mass and Shield into the Vacuum Vessel.

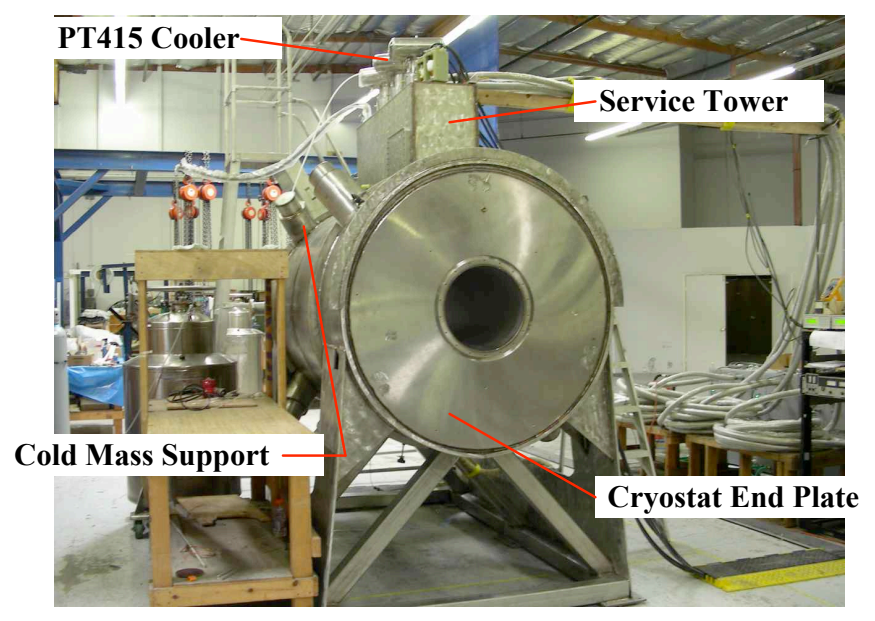

Fig. 8. The Finished First Spectrometer Solenoid Ready for Cool-down.

\section{SOME CONCLUding COMMENTS}

The magnet was cooled down to $4 \mathrm{~K}$, and it was powered to seventy percent of its maximum design current. Magnet training was stopped in June 2008 because the heat load into the magnet wasn't going to the coolers. There were a number of problems that were unearthed during the first test of the magnet. The problems that occurred during the first magnet test are described in [11]. The results of the magnet test show that the magnet cannot be run in the MICE cooling channel as it was built. As a result, the magnet will be rebuilt and retested in early 2009.

\section{REFERENCES}

[1] R. B. Palmer, A. Sessler, A. Skrinsky, A. Tollestrup, et al, "Muon Colliders," Brookhaven National Laboratory Report BNL-62740, January 1996.

[2] G. Gregoire, G. Ryckewaert, L. Chevalier, et al, "MICE and International Muon Ionization Experiment Technical Reference Document," http://www.mice.iit.edu, 2001.

[3] S. Q. Yang, M. A. Green, et al, "The Mechanical and Thermal Design for the MICE Focusing Solenoid Magnet System," IEEE Transactions on Applied Superconductivity 15, No. 2, p 1259, (2005).

[4] L. Wang, M. A. Green, F. Y. Xu, H, Wu, et al, "The Engineering Design of the $1.5 \mathrm{~m}$ Diameter Solenoid for the MICE RFCC Modules, IEEE Transactions on Applied Superconductivity 18, No. 2, p 937, (2008).

[5] M. A. Green, C. Y. Chen, T. Juang, W. Lau, et al, "The Design Parameters for the MICE Tracker Solenoid," IEEE Transactions on Applied Superconductivity 17, No. 2, p 1247, (2007).

[6] P. Fabricatore, S. Farinon, U. Bravar, et al, "The Mechanical and Thermal Design for the MICE Detector Solenoid," IEEE Transactions on Applied Superconductivty 15, No. 2, p 1255 (2005).

[7] X. L. Gou, F. Y. Xu, L. Wang, M. A. Green et al, "Quench Protection for the MICE Cooling Channel Coupling Magnet," submitted to IEEE Transactions on Applied Superconductivity 19 (this issue), August 2008.

[8] M. A. Green, "A Design of a Rapid Discharge System for the MICE Magnet Circuits," MICE Note 208, http://www.mice.iit.edu, June 2008.

[9] M. A. Green, L. Wang, X. L. Gou, F. Y Xu and L. X. Jia, "Quench Protection for the MICE Coupling Magnet," LBNL-63698, MICE Note 193, http://www.mice.iit.edu, 20 November 2007.

[10] M. A. Green and S. T. Wang, "Tests of Four PT415 Coolers Installed in the Drop in Mode," to be published in the Proceedings of ICEC-22, Seoul Korea, 21 to 25 June 2008.

[11] S. P. Virostek, M. A. Green, D. Li et al, "Preliminary Test Results for the First MICE Superconducting Spectrometer Solenoid," submitted to IEEE Transactions on Applied Superconductivity 19, No. 3, (this issue), 2008 
DISCLAIMER

This document was prepared as an account of work sponsored by the United States Government. While this document is believed to contain correct information, neither the United States Government nor any agency thereof, nor The Regents of the University of California, nor any of their employees, makes any warranty, express or implied, or assumes any legal responsibility for the accuracy, completeness, or usefulness of any information, apparatus, product, or process disclosed, or represents that its use would not infringe privately owned rights. Reference herein to any specific commercial product, process, or service by its trade name, trademark, manufacturer, or otherwise, does not necessarily constitute or imply its endorsement, recommendation, or favoring by the United States Government or any agency thereof, or The Regents of the University of California. The views and opinions of authors expressed herein do not necessarily state or reflect those of the United States Government or any agency thereof, or The Regents of the University of California. 